\title{
Six critical dimensions: A model for widening participation in open, online and blended programs
}

\author{
Sarah R. Lambert
}

Deakin University

\begin{abstract}
Working from the perspective of open and online learning for widening participation in higher education, this article advances a new conceptual model to guide practitioners and researchers in maximising the enablers and minimising the constraints to foundation level online learning for equity students. The model is adapted from technology for social inclusion research addressing persistent inequalities in Internet use. First, the proposed model is introduced with definitions for the six dimensions (course purpose, technology, social support, autonomy, learning materials and skills) and research propositions for how the dimensions enable and constrain learning. A qualitative synthesis of empirically tested open and online programs (including massive open online courses) is used to clarify how the six critical dimensions interact to enable and constrain diverse learners in distance and blended modes. Results support the model with new definitions for each dimension in light of unexpected findings: courses designed to enable particular groups; breadth of learner supports; technology amplifying other dimensions; and aspects of the model designed to empower disadvantaged learners. This model should assist course design research and practice at higher education institutions where open and online provision for diverse and educationally disadvantaged learners is the current or approaching reality.
\end{abstract}

\section{Implications for practice or policy:}

- Learning designers and educators can use the new model to work on improvements to the quality and support of their blended or online courses at the same time as increasing equity.

- Course access, progression and success rates could be improved overall by lifting outcomes for all learners, including transitioning, foundational and non-traditional or equity students.

- Researchers of digital equity can use the model as an analytic tool to evaluate open and online courses.

Keywords: equity, inclusion, disadvantage, design model, qualitative synthesis

\section{Introduction}

Ever since the rise of the Internet, the problem of digital inequality and digital divides has been a concern for society, educators and policymakers. Early research on digital divides found there were "gaps in access to computers and the Internet among individuals and groups based on race, gender, socioeconomic status, first language, disability, and other social or cultural identities (Gorski, 2003, p. 458)." The goal of digital equity is to bridge digital divides so that all members of society can access and use digital technologies effectively. Digital equity is more than owning a computer or smartphone. It is about "social and economic participation: using online and mobile technologies to improve skills, enhance quality of life, educate, and promote wellbeing across the whole of society" (Thomas et al., 2017, p. 7).

As the previous quote illustrates, digital equity is a challenge for society and also specifically for education, which increasingly relies on online provision. The need for digital equity adds to the complexities of widening access and participation in higher education, which despite transformation in recent decades from elite to mass to almost universal access (Trow, 2005), still is not equally available to all.

Widening participation policies in higher education seek to improve the access and success of underrepresented students from various government-defined equity groups (Bennett, Southgate, \& Shah, 2016) and increasingly do so through online means (Devlin, 2018). Definitions of equity students vary from country to country, but commonly include low socio-economic, first-in-family to attend university, regional and remote, indigenous, women in science and technical disciplines, and learners with disabilities or from non-English speaking backgrounds (Bennett et al., 2016). Students from these equity groups (herein called 
equity students) have lower rates of higher education participation and success, so lifting their participation is important to address societal inequalities. Online education for equity students seems to be both a blessing and a curse. On the one hand, it makes study possible for many mature-age, regional, disabled and indigenous learners often juggling work, study and caring for children or elders. On the other hand, retention, progression and graduation rates for online learners are typically much worse than for campusbased learners.

Open education, including provision by open universities, is an area of practice and scholarship experienced in improving access to education for those typically excluded, including addressing widening participation through digital means. Open education is an umbrella term for a range of approaches to education "that seeks to remove all unnecessary barriers to learning, while aiming to provide students with a reasonable chance of success" (Butcher, 2015, p. 6). Since equity learners often have limited schooling experiences and outcomes, open education often involves the provision of foundational and bridging courses and/or recognition of prior and workplace learning, so that learners are not unnecessarily barred from educational opportunities by lack of appropriate skills and qualifications.

Massive open online courses (MOOCs) are a recent innovation in open education that aimed to make a contribution towards widening participation and reducing digital inequality. As well as eliminating educational qualifications prior to entry, MOOCs were also first provided free to the learner thus also removing the cost barrier to university level online courses. While the first generation of MOOCs were taken up by the already educated and relatively privileged (Emanuel, 2013; Rohs \& Ganz, 2015), by 2014 the MOOC landscape had matured and diversified so that "MOOCs 2.0" got better at attracting and retaining students, including those typically excluded from higher education (Hyman, 2013; Lambert, 2020). A recent systematic review study I undertook found that there "was a flourishing of multi-lingual and Languages other than English (LOTE) programs and those addressing regional socio-economic disadvantage ... (and that) MOOCs which aim to widen participation in education are an alternative global practice that exists alongside more commercial MOOC offerings" (Lambert, 2020, p. 1). MOOCs from 2014 were found to enable the digital equity of students preparing for and studying in higher education as well as enabling community members with a need for up-to-date information on a particular topic but no aspiration for a formal qualification. This was achieved in a variety of ways, including by providing lowbandwidth mobile-friendly options, culturally inclusive foundational rather than advanced content and additional forms of face-to-face and online support including orientation to the skills required for online learning. These strategies would be familiar to practitioners of mainstream online and blended learning, particularly for foundational and undergraduate-level courses. Indeed, as MOOCs are embedded in forcredit campus courses and introduce options for-fee micro-credentials and pathways to regular university credentials, they are becoming more similar to mainstream online university provision (Kent \& Bennett, 2017).

This article reports on a follow-up study to Lambert (2000), which aims to synthesise learners' experience within recent widening participation MOOCs to advance a new multidimensional model adapted from the literature of technology for social inclusion. The model aims to guide practitioners and researchers to maximise the enablers and minimise the constraints to foundation level online learning for equity students. This is a timely contribution since as the following literature review section shows, conceptual models that provide course designers with guidance on how to meet the challenges of widening participation and reducing digital inequality are currently lacking.

In developing the model, I adopted a foundational belief from the internationally recognised field of inclusive education - that designing inclusively with equity students in mind will benefit all students, not just equity students (Florian \& Black-Hawkins, 2011).

\section{Literature review}

The introduction has briefly provided definitions and purposes of digital equity, widening participation, and open education (including MOOCs). This section will focus on the limitations of existing conceptual models in relation to online course design and equity students, before introducing an alternative model derived from a related field. The six critical dimensions for widening online participation model is developed through application to specific empirical studies identified by a systematic review. 


\section{Conceptual models for online learning and equity students}

Conceptual models for complex social contexts, such as education, tend to feature a range of dimensions or factors that explain outcomes of a phenomenon, as well as some kind of logic that explains the relationship between the dimensions. This makes them useful for both design and research.

Research grounded in conceptual models avoids repetition and fragmentation, minimises descriptive studies that cannot be applied in other contexts (Bozkurt, Akgün-Özbek, \& Zawacki-Richter, 2017) and promotes the cumulative knowledge-building needed to move the field of educational technology forward (Howard \& Maton, 2011).

Transactional distance (TD) and community of inquiry (CoI) are the most popular models used in published online and distance learning research (Bozkurt, Kilgore, \& Crosslin, 2017). TD was developed during the period of distance education's transition from analogue to digital delivery, adjusting from text to audiovisual media such as television and CD-ROM then to online communications tools and learning management systems (Anderson \& Dron, 2011; M. G. Moore, 1993). The three dimensions of TD (dialogue, structure and autonomy) are useful for understanding the psychological and communication distances created in distance education programs when students and teachers do not have classroom contact.

In the TD model, learner difference is confined to the learner autonomy dimension, which is limited in its conceptualisation of diversity to independent versus dependent learners. Studies to bring the model up to date with changes in contemporary web-based learning environments had limitations in that they also examined privileged groups of learners: experienced graduate distance education learners enrolled in business or education courses at North American universities (MacLeod, Swart, \& Paul, 2019; Paul, Swart, Zhang, \& MacLeod, 2015). I therefore suggest that the model has not been adapted for higher education's transition from elite to mass access and the influence of widening participation agendas globally. It is also focused on solving the problems of distance learning rather than blended learning which still has face-toface contact.

The CoI model investigates teacher, cognitive and social "presences" thought to be necessary elements for effective communications within a community of learners (D. R. Garrison, Anderson, \& Archer, 2010 ; R. Garrison, 2000). The CoI is a relatively new model that has mostly been used to analyse online discussion forum interaction and to investigate student perceptions of courses via a structured survey (Stenbom, 2018). A recent systematic review of studies using the CoI student perceptions survey concluded that it would need expansion if it was to be applied beyond online communications "in order to make more general claims about the nature of online and blended learning" (Stenbom, 2018).

However, the CoI model was not designed with the intention of investigating online learning in a general sense; rather, it was designed specifically to investigate the development of higher-order learning and critical thinking skills through discussion-based collaborative pedagogies (Kozan \& Caskurlu, 2018). This is a very specific and different purpose to widening participation of equity students in foundational undergraduate studies. This may explain why the CoI model has been applied only to research on a limited range of subjects, mostly for postgraduate level learners (Stenbom, 2018).

A lack of understanding of learner diversity in the CoI model can be seen in the way teachers or learners (and related to this, their cognition) are primarily conceptualised by their presence (or absence), and as such are positioned as homogenous. This is problematic for many online learning contexts featuring learners with diverse socio-economic and cultural backgrounds. In addition, the logic of the model, which assumes that learner and teacher presence are good, is not borne out by research into classist, sexist and racist encounters in online environments, where non-privileged learners can be bullied, intimidated and silenced by higher-status and more confident learners (Funes \& Mackness, 2018; Gorski, 2009). Perhaps for these reasons the CoI model has not been shown empirically to be useful for investigating the success of equity students. For example, a large-scale study of the CoI model with community college students (equity students) in the United States of America found that students' perceptions of presence had no relationship to academic completion and, in fact, "no significant differences between course completers and noncompleters on any CoI indicators or demographic/status variables are found" (Traver, Volchok, Bidjerano, \& Shea, 2014, p. 1). 
Researchers into widening participation are increasingly interested in understanding how campus-based institutions can do better for equity students and online learning but has yet to develop conceptual models to guide curriculum development. Studies often develop recommendations synthesised from staff and student interviews and offer insights into what higher education institutions can do to be more welcoming and supportive of equity students who are studying online (Devlin, 2018; Stone, 2017; Tait, 2015). Examples include knowing who students are, embracing difference, developing sociocultural capability necessary for university success, university-wide coordinated effort and content and curriculum designed specifically for online learning. These are very important to shift organisational culture and outdated deficit discourse, which focuses too much on what equity students lack rather than on their strengths and capabilities such as agency, maturity, experience and determination. However, while the recommendations can help universities plan and structure their services in a better way, they are not finely grained enough to guide the design of curriculum.

There has also been a recent report into inclusive technology-enhanced learning environments based on universal design for learning. The research was guided by an overarching framework of overlapping concerns derived from the literature: accessibility, useability, personalised learning and pedagogy (Wood, Scutter, \& Viljoen, 2016). This produced a useful set of guidelines focused on the fine-grained accessibility and usability of online learning platforms by individual learners, such as links, resource formats and signposting, alternative text for screen readers (used by vision-impaired learners) and consistent navigation and terminology.

The gap in the literature that this article seeks to address is for a conceptual model designed for and derived from empirical studies of equity students' participation and success in online education. It needs to be midrange in scope to suit the design of units and courses - finer grained than organisational principles and recommendations (macro-level theorising), yet not as micro-level as online platform usability.

\section{A new model developed from digital inequality literature}

There has been useful research that has provided models for fairer use of Internet technologies, which I propose is a good starting point to develop a model of using the Internet more fairly in education contexts. Technology for social inclusion literature has highlighted how cultural contexts and social support impact both the use and relative benefits of technologies (Warschauer, 2003). Noticing the tendency for new technologies like mobile phones and the Internet to benefit the already advantaged in ways that echo early MOOC adoption, the concept of the digital divide was developed to explain how Internet-delivered services - including education - can both include and exclude (Brown, Barram, \& Irving, 1995). However, the notion of a one-dimensional divide between the haves and have-nots was found to be simplistic and limiting (DiMaggio \& Hargittai, 2001; Liff, Shepherd, Wajcman, Rice, \& Hargittai, 2004). It was not just the access to Internet-enabled computers, but a person's time, skills and opportunities to make use of such technology for their own benefit that determined whether technology produced equitable experiences.

Increasing Internet penetration ensuring nearly everybody has access in some form does not mean inequality will be eliminated, but instead more nuanced forms of inequality will emerge between different types of Internet users, that is, broadband versus mobile-only users "in the extent to which they are able to reap benefits from their use of the technology" (DiMaggio \& Hargittai, 2001, p. 7). The potential benefits include a fairer distribution of the improved socio-economic outcomes that flow from access to information and services, including education. DiMaggio and Hargittai identified five forms that inequality of Internet use can take, which they called "five critical dimensions", that is, technology, autonomy, purpose, social support and skills - these are defined in the next section. They proposed that the five dimensions need to be considered in the implementation of technologies so as to avoid deepening digital divides. As these five dimensions have been developed from a theoretical base relating to digital equity and learner diversity, they seem likely to be usefully adapted for digital equity of education settings.

\section{Adapting for open and online education: from five to six critical dimensions}

This article proposes that DiMaggio and Hargittai's (2001) five critical dimensions model can be applied to research to explain why some online educational programs engage and enable non-privileged learners and others do not. However, because the model is based on general Internet use, it needs to be adapted for educational settings. Therefore, I added a sixth dimension, learning materials, which is essential for open 
online education programs including MOOCs (Bates, 2012; Bonk et al., 2018; Conole, 2013). Learning materials include text, audiovisual materials, tasks and assessment items, which are often presented to the learner side by side in MOOCs. Learning materials are also a known site of inequality because of differences in costs, access, language of instruction, topic and learning levels (Colvard, Watson, \& Park, 2018; Laurillard \& Kennedy, 2017).

Considering the literature on digital equity about the need for affirming and non-hostile content (Gorski, 2009) and literature on widening participation, which recommends that higher education (including its curriculum) welcomes learners from diverse social, cultural and linguistic backgrounds, learning materials might also need to be inclusive of this sociocultural diversity (Devlin, 2012; Mountford-Zimdars et al., 2015).

Table 1 provides a comparison of the original definitions of the five dimensions and the updated six critical dimensions model, all drawn from the literature addressing online learning and equity students.

Table 1

Definitions for the six dimensions of widening online participation model developed from literature

\begin{tabular}{|c|c|c|}
\hline Dimension & $\begin{array}{l}\text { Original definition (DiMaggio } \\
\text { \& Hargittai, 2001, p. 8) }\end{array}$ & $\begin{array}{l}\text { Definition updated for open and online } \\
\text { education }\end{array}$ \\
\hline Technology & $\begin{array}{l}\text { The extent that technical means } \\
\text { enable access to the web, i.e., } \\
\text { hardware and connections. }\end{array}$ & $\begin{array}{l}\text { The degree of ease to access and use of free } \\
\text { hardware, free online courses and resources } \\
\text { including on mobiles and over Wi-Fi } \\
\text { (Negroponte, Bender, Battro, \& Cavallo, } \\
\text { 2006) }\end{array}$ \\
\hline Autonomy & $\begin{array}{l}\text { The extent to which people can } \\
\text { exercise autonomy in their use of } \\
\text { the web, i.e., from home or work, } \\
\text { monitored or unmonitored and } \\
\text { competition with others for } \\
\text { shared equipment and/or time } \\
\text { online. }\end{array}$ & $\begin{array}{l}\text { The extent that learners have choice and } \\
\text { control over where, when and how much } \\
\text { they choose to study and contribute without } \\
\text { social, gender or role pressures (Funes \& } \\
\text { Mackness, 2018; Mackness, Mak, \& } \\
\text { Williams, 2010) }\end{array}$ \\
\hline Purpose & $\begin{array}{l}\text { The extent that the Internet is } \\
\text { used for education and } \\
\text { development rather than only for } \\
\text { entertainment. }\end{array}$ & $\begin{array}{l}\text { The degree to which topics are intended to } \\
\text { improve socio-economic opportunities and } \\
\text { outcomes for learners with limited prior } \\
\text { education rather than reinforcing existing } \\
\text { inequalities (Tait, 2015) }\end{array}$ \\
\hline Skills & $\begin{array}{l}\text { Inequalities in the skills that } \\
\text { people bring to their use of the } \\
\text { Internet. }\end{array}$ & $\begin{array}{l}\text { The extent that programs can overcome } \\
\text { inequality in pre-existing digital and } \\
\text { information literacy skills to navigate online } \\
\text { learning, submit assignments and } \\
\text { communicate with others (Beaven, Hauck, } \\
\text { Comas-Quinn, Lewis, \& de los Arcos, 2014) }\end{array}$ \\
\hline Social support & $\begin{array}{l}\text { Inequality in the social support } \\
\text { on which Internet users can } \\
\text { draw. }\end{array}$ & $\begin{array}{l}\text { The extent that programs can overcome } \\
\text { inequality in social support, i.e., online } \\
\text { forums and/or face-to-face opportunities to } \\
\text { discuss learning including acknowledging } \\
\text { social networks that learners already have } \\
\text { access to (Daniel, 2012; Engstrom \& Tinto, } \\
\text { 2008; M. Moore \& Tait, 2002; Simpson, } \\
\text { 2008) }\end{array}$ \\
\hline Learning materials & N/A & $\begin{array}{l}\text { The extent to which textual, audiovisual } \\
\text { materials, assessment and feedback are } \\
\text { inclusive of learners' sociocultural and } \\
\text { linguistic diversity (Devlin, 2018; Gorski, } \\
\text { 2009; Yosso, 2005) }\end{array}$ \\
\hline
\end{tabular}


In addition to the existence of the dimensions, I have developed the following research propositions, drawing on the literature of learner agency and strengths to explain learner outcomes in terms of how the dimensions within the model interact with each other and with the learner:

- Proposition 1 (P1): Each of the six critical dimensions will be present in the design or experience of the course to some degree and each will have some kind of influence on the outcomes for equity students.

- Proposition 2 (P2): Each of the six critical dimensions can either enable or constrain learners, and more successful courses enable more than they constrain

- Proposition 3 (P3): Learner agency (goals, motivations, acting to overcome obstacles) also influences course outcomes.

The first two propositions, while not explicit, are developed from the logic of DiMaggio and Hargittai's (2001) original writings and are important to further define and operationalise the model.

I developed the third proposition from the literature on theories of agency (Archer, 2003), which is useful in considering and explaining the role of the learner in their learning. In the context of courses, the concept of learner agency suggests that the same course can both enable and constrain different learners in different circumstances. This is particularly the case where social rules and stereotypes (known as social structures) can limit ideas of what is suitable and socially acceptable for some people to do (Archer, 2003). For example, it is not common for women to become tradespeople or engineers, but nevertheless, some feel strongly enough that this career is for them and will follow a path to achieve that goal, despite the difficulties faced along the way. By considering the theory of agency, the model incorporates the possibility that any of the dimensions can be experienced positively or negatively because of learner diversity.

When a course is experienced negatively (i.e., it constrains a learner), the concept of agency mediates the outcome - more agentic learners will find ways to work around the problems they experience so they can meet their larger goal, while others will be sufficiently deterred and quit (Case, 2013; Mackness \& Pauschenwein, 2016). The terms enable and constrain not only denote the positive/negative possibilities of the proposed logic of the model but were also used by Archer (2003) in her development of the concept of agency.

Therefore, the research method described in the next section was developed to investigate how the six critical dimensions might explain both the enablement and constraint of disadvantaged learners in open online courses.

\section{Methodology: qualitative synthesis of representative case studies}

In the field of education (as in the social sciences), new conceptual models are a form of theorising that helps to explain why people act the way they do in particular educational settings (Biesta, Allan, \& Edwards, 2011). This article proposes that the six critical dimensions model is useful for explaining the progress and success (or lack of progress and success) of disadvantaged students in open online courses.

This study investigated the usefulness of the model's explanatory power within a representative sample of open online programs (including MOOCs) to examine if the model can make the leap from examining the equity of general Internet use to examining the equity of Internet use in educational settings.

Syntheses of case studies identified in systematic reviews have been used since the 1990s as a useful knowledge-building and theory-generating method because they bring together and make meaning from findings across multiple investigations (Bearman \& Dawson, 2013; Finfgeld, 2003; Pawson, Greenhalgh, Harvey, \& Walshe, 2005). This helps scholars address the challenge of moving "knowledge development and theory generation forward based on findings from isolated qualitative research investigations" (Finfgeld-Connett, 2014, p. 341). A systematic review of the literature was therefore used to locate a globally representative sample of case studies of open online programs designed to enable disadvantaged learners. Searches were limited to journal articles and reports published since 2014 when - as discussed in the Literature review section - MOOC practice had matured and governmental and philanthropic providers 
began to use MOOCs in both distance and blended modes to widen participation of underserved learners. Empirical case studies were included' policy or pilot accounts were excluded.

A qualitative synthesis of the findings was used to address the three research questions noted in the previous section. Qualitative synthesis is a form of analysis of qualitative data (Finfgeld-Connett, 2014; Sandelowski, Voils, Leeman, \& Crandell, 2012). To address P1, a range of text-based data was extracted from the case studies regarding the aim of the program in relation to particular disadvantaged learners, the extent to which the program succeeded with its aims, and which of the six critical dimensions were noted from the design and research accounts to have influenced the outcome. A simple measurement system was applied to rate the extent to which each dimension was noted to enable or constrain learning. This method allows for analysis of which dimensions are more influential as enablers and constraints. Qualitative synthesis allows for a refinement of the definitions so that the design elements most influencing outcomes are included within the definition of each dimension. To address P2, the case studies were also grouped by level of outcomes and comparisons were made between the dimensions that most enabled and constrained in the more successful cases versus the less successful cases. Success was determined by comparing the actual outcome to the stated aim using a simple measurement scale: exceeded aims, met aims, mixed outcomes, underperformed. To address P3, the data collected for P1 was additionally analysed for evidence of learner agency, particularly in overcoming the constrains of the dimensions. As a result of the findings, the definitions of the model's dimensions were refined to reflect the factors within each dimension that could most clearly be seen to explain the enablement or constraint of learning. The refinement of emergent models through cycles of theorising and empirical synthesis can subsequently improve program outcomes, enhance research and shape policy (Finfgeld-Connett, 2014; Pawson et al., 2005). The improved model is therefore likely to be useful for educators, designers and researchers of foundational online programs that seek better outcomes for equity students.

Figure 1 provides a visual overview of the method used to develop the new model. It shows the steps used to investigate the extent that the six critical dimensions are useful for explaining the enablement or constraint of disadvantaged learners in open online programs.

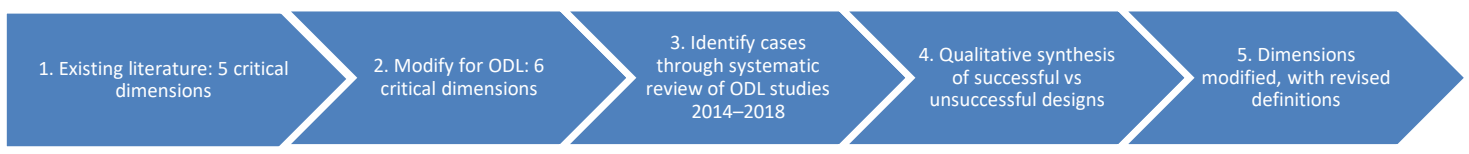

Figure 1. Methodology of development of the new conceptual model (ODL = open and distance learning)

\section{Results: six dimensions explain both enablement and constraint of learning}

Through focused searches in Scopus and Google Scholar databases, the systematic review identified 22 empirical case studies of online programs which aimed to reduce educational inequality for equity students. This number (22) constitutes a suitable number (above the average of 14) of studies for qualitative synthesis; too many studies can overwhelm and exceed a saturation point where additional insights are not made (Finfgeld-Connett, 2014). Key statistics about the programs were recorded and tabulated. In total, the programs included in the 22 studies reached 449,403 learners, and collected over 320,726 pieces of learner data, including 28,193 survey results. A full account of the descriptive statistics and concerns of the literature can be found in Lambert (2020).

The sample of 22 case studies was found to be representative of open education and MOOC 2.0 practice: socio-culturally and linguistically diverse; courses of varying timeframes; class sizes ranging from small and modest to massive; offered in distance or blended learning situations often with weekly face-to-face classes; and in numerous different global contexts (Lambert, 2020). Of the 22 courses, 27\% (6) were of about a semester's length (10-13 weeks), and 45\% (10) were 6-9 weeks long. Of the courses of 6-13 weeks long, about a third $(30 \%-33 \%)$ had weekly face-to-face classes. These statistics about the sample of courses illustrate the way that MOOCs 2.0 have features in common with regular online university courses.

The next sections will address results for each of the three research propositions in turn. 
In terms of P1 (presence of all six dimensions impacting outcomes), the results support the proposed model and the existence of the six dimensions as useful explainers of enablement or constraint of equity students in online learning contexts. For example, although peer learning and support often enabled learning, when online forums excluded or overwhelmed learners, the social support dimension was found to constrain learners. When learners had some choice and control over their learning, the autonomy dimension was found to enable learning; however, if there was too much autonomy, learners were constrained by feeling isolated and unsupported. In some cases, a total lack of consideration of a dimension seemed to constrain learning.

The analysis also suggests that each dimension does not equally influence outcomes in that:

- $\quad$ some dimensions enabled more than others

- $\quad$ some dimensions constrained more than others

- the reported constraints were fewer than the reported enablements.

As Figure 2 shows, across the full set of studies $(N=22)$, the top three dimensions most frequently found to enable outcomes were course purpose, technology and social support, closely followed by autonomy and learning materials. Skills were discussed the least as either enablers or constraints. Note that in Figure 1, because of the 0-1-2 measurement scale, a maximum score of 44 is possible on the $\mathrm{x}$-axis (22 studies $\mathrm{x} 2$ points). The same dimensions were also noted to constrain learning, but only around a third as much as the dimensions were noted to have enabled learning. It is not clear if this is due to the underreporting of constraints, or if the enabling effect was stronger than the constraining effect.

The "other" dimensions were common to the broader education literature and included a suitable time commitment from learners, teacher training and workload allocation of teachers and facilitators. Therefore, these do not justify becoming a seventh dimension as they are not specific to online learning.

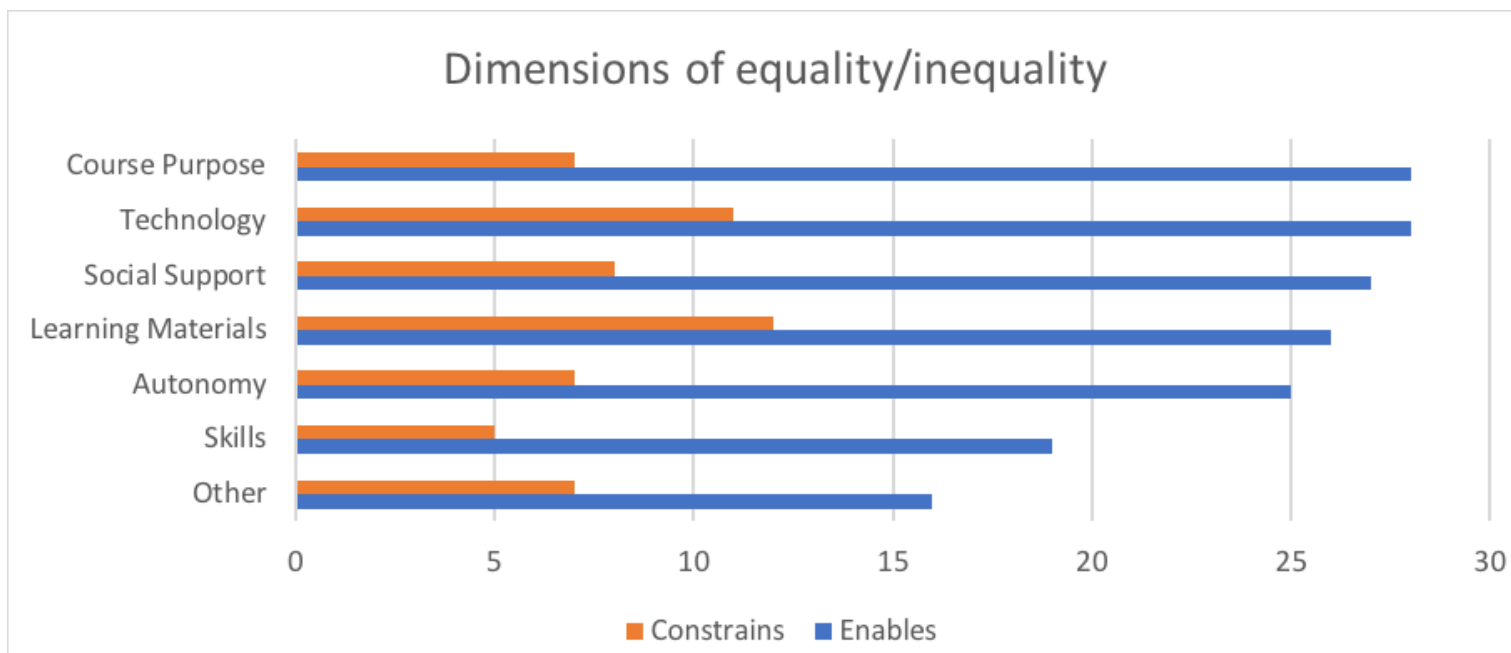

Figure 2. The frequency the critical dimensions either enable or constrain learning across all programs in the study on a scale of $0-44$ (maximum 2 points for 22 studies)

However, in terms of P2 (dimensions as enabling or constraining learners), when comparing the incidences of the critical dimensions for the 12 more successful programs (met or exceeded published aims) with the 10 less successful programs (mixed outcomes or underperformed compared to published aims), a very different picture emerged. Table 2 provides a summary listing of all the studies, their outcomes and the degree to which each dimension enabled or constrained. 
Table 2

Summary of studies, outcomes and dimensions (CP, Tech, LM, SS, Aut, Skl) with scores for enablers (+) and constraints (-)

Study number, summary and reference Outcome

Scoring of dimensions as enablers $(+)$ or constraints (-)

1. The University of Tasmania's Understanding Dementia MOOC enabled older women with low prior levels of education (Goldberg et al., 2015; King et al., 2014).

2. e-readers, weekly study groups and online support raised the confidence and academic outcomes of

Chilean first-in-family pre-service teachers needing to teach in English, and at risk of failing

(Charbonneau-Gowdy, Capredoni, Gonzalez, Jayo, \& Raby, 2015).

3. A thoughtfully facilitated Taiwanese MOOC study group program enabled learners to meet their own objectives including sharing and improving study and time-management skills (Chen \& Chen, 2015).

4. A first-year foundation STEM program formed study groups to learn from a MOOC aligned with their formal course materials (N. Li, Kidzi, \& Dillenbourg, 2015).

5. The Sustainable Development MOOC platform (Celina, Kharrufa, Preston, Comber, \& Olivier, 2016)

was customised to facilitate complex group projects undertaken both face-to-face and online, on a development topic of learner interest.

6. Large-scale Indian multiregional multilingual teacher training MOOC with weekly study groups delivered on mobiles. Classes with laptops/connectivity were rare (Wolfenden, Cross, \& Henry, 2017).

7. AuthorAID research writing MOOC enabled the inclusion and development of large numbers of female, regional, Global South participants with family responsibilities who had been noticeably underrepresented in previous face-to-face programs (Murugesan, Nobes, \& Wild, 2017).

8. Digital Families program provided workshops and free handheld devices for parents and children with learning disabilities to explore and become confident using apps useful for their particular learning needs (McDougall, Readman, \& Wilkinson, 2016).

9. OpenLearn free online modules for university preparation, employability and community volunteering Met aims (Law, 2015).

10. The NovoEd MOOC platform was customised to enable virtual teamwork, team members negotiated Met aims roles and tasks (Wen, Yang, \& Rose, 2015).

11. The Recommender tool facilitated student-suggested and -voted resources on the edX MOOC Met aims platform (S. Li \& Mitros, 2015).

12. A niche medical MOOC for workers to upskill into more professional roles (Milligan \& Littlejohn, Met aims 2016).

\begin{tabular}{llllllll} 
& \multicolumn{2}{l}{ constraints (-) } \\
\cline { 2 - 8 } & & CP & Tech & LM & SS & AT & SK \\
\hline Exceeded & + & 2 & 2 & 2 & 2 & 2 & 2 \\
aims & - & 1 & nd & nd & nd & nd & nd \\
\hline $\begin{array}{l}\text { Exceeded } \\
\text { aims }\end{array}$ & + & 2 & 2 & 1 & 2 & nd & 2 \\
\cline { 2 - 8 } & - & nd & nd & nd & 0 & nd & nd
\end{tabular}

Exceeded aims

Exceeded aims

Exceeded aims

\begin{tabular}{lll}
+ & 1 & 2 \\
\hline- & 1 & nd \\
\hline+ & 1 & 1 \\
\hline- & nd & 0 \\
+ & 2 & 2 \\
\hline- & nd & 1
\end{tabular}

Exceeded aims

Exceed

nd nd 1

Met aims

\begin{tabular}{lllllll}
+ & 2 & 2 & 2 & 2 & 2 & 2 \\
\hline- & 1 & 1 & 1 & nd & nd & nd \\
\hline+ & 2 & 1 & 2 & 2 & 2 & 1 \\
\hline- & nd & 1 & nd & nd & nd & nd
\end{tabular}

ms

\begin{tabular}{lllllll}
+ & 2 & 2 & nd & 2 & 2 & 2 \\
\hline- & 1 & 1 & nd & 1 & nd & 0
\end{tabular}

\begin{tabular}{lllllll}
+ & 2 & 2 & 2 & nd & 2 & 2 \\
\hline- & nd & 1 & 1 & nd & nd & nd \\
\hline+ & nd & 2 & nd & 0 & 1 & 2 \\
\hline- & nd & nd & nd & nd & nd & nd \\
\hline+ & 0 & 1 & 1 & 1 & 1 & nd \\
\hline- & nd & nd & nd & 1 & 0 & nd \\
\hline+ & 1 & 2 & 2 & 2 & 2 & 1 \\
\hline- & nd & 0 & 2 & 1 & nd & 1 \\
\hline
\end{tabular}


13. Analysis of a cMOOC using WordPress and social media for information and communication technology professional development of teachers (S. Li, Tang, \& Zhang, 2016).

14. Coursera Pre-College English Writing MOOC was specific to US context rather than a global cohort of learners and could not be modified after course start (Whitmer, Schiorring, James, \& Miley, 2015).

15. The Human Trafficking MOOC enabled attitudinal change about a vulnerable community who were represented in the forums and videos, online forums were at times very heated (Watosn et al., 2016). 16. The EU funded Hands-On ICT (HANDSON) MOOC for teachers included forums facilitated in seven different mother tongues: English, French, Greek, Slovenian, Bulgarian, Catalan and Spanish (Colas, Sloep, \& Garreta-Domingo, 2016). Culturally cohesive groups were more engaged, participated more.

17. College preparation or gateway programs (Stich \& Reeves, 2017) were contingent on pitching the content to the correct entry level so that a safe space and modest pace could be provided for beginners.

18. eTutor algorithms for revising technical topics increased the speed of revisions, but not the depth of learning 9TEkin \& van der Schaar, 2015).

19. Nanotechnology MOOC in Arabic reached fewer learners than anticipated, learners mostly used the

English version despite careful translation (Barak, Watted, \& Haick, 2016).

20. The Entrepreneurship and Innovation in IT MOOC was set up to enable groups to develop a new ITrelated business plan, but the group-work aspect did not succeed, and instead those who completed did the work individually (MacKinnon \& Bacon, 2016).

21. Four optional remedial STEM MOOCs for first-year learners with low take-up and little impact on learning (Pérez-Sanagustín, Hernández-Correa, Gelmi, Hilliger, \& Rodriguez, 2016).

22. Low take-up and negligible impact of optional steps into foundation STEM MOOCs to try and improve study skills (Davis et al., 2016).

\section{constraints (-)}

Mixed

outcomes

Mixed

outcomes

Mixed

outcomes

Mixed

outcomes

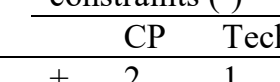

Tech

LM 1 SS

\begin{tabular}{lll} 
SS & Aut & Skl \\
\hline 2 & nd & 2 \\
\hline 1 & 2 & 2 \\
1 & 1 & 1 \\
\hline 1 & 1 & nd \\
\hline 2 & 2 & 1 \\
\hline 2 & 2 & 0 \\
\hline 2 & 2 & 1 \\
1 & nd & 1
\end{tabular}

\begin{tabular}{|c|c|c|c|c|c|c|c|}
\hline \multirow{2}{*}{$\begin{array}{l}\text { Mixed } \\
\text { outcomes }\end{array}$} & + & 1 & nd & 1 & nd & nd & nd \\
\hline & - & nd & nd & 1 & nd & nd & nd \\
\hline \multirow{2}{*}{$\begin{array}{l}\text { Mixed } \\
\text { outcomes }\end{array}$} & + & 2 & nd & 2 & nd & 0 & nd \\
\hline & - & nd & nd & nd & nd & nd & nd \\
\hline \multirow{2}{*}{$\begin{array}{l}\text { Mixed } \\
\text { outcomes }\end{array}$} & + & 2 & 2 & 1 & 2 & 2 & 2 \\
\hline & - & 1 & nd & nd & nd & nd & nd \\
\hline \multirow{2}{*}{$\begin{array}{l}\text { Under- } \\
\text { performed }\end{array}$} & + & 2 & nd & nd & 0 & 0 & nd \\
\hline & - & 2 & nd & nd & 2 & nd & nd \\
\hline \multirow{2}{*}{$\begin{array}{l}\text { Under- } \\
\text { performed }\end{array}$} & + & 2 & 1 & 1 & nd & nd & 1 \\
\hline & - & 1 & 1 & 2 & nd & nd & nd \\
\hline \multirow{2}{*}{$\begin{array}{l}\text { Under- } \\
\text { performed }\end{array}$} & + & 0 & 0 & 0 & nd & 0 & 0 \\
\hline & - & 0 & 1 & nd & nd & 2 & nd \\
\hline
\end{tabular}

Key to scores: 2 = major impact on outcomes, $1=$ minor impact on outcomes, $0=$ no impact was noted or not important, nd $=$ not discussed 
As Figures 3 and 4 show, social support, autonomy and technology were the top three most frequent enablers noted by the studies of the more successful programs, whereas the less successful programs relied on the dimensions course purpose, technology and learning materials as enablers.

\section{Balance between enablement and constraint in more successful programs}

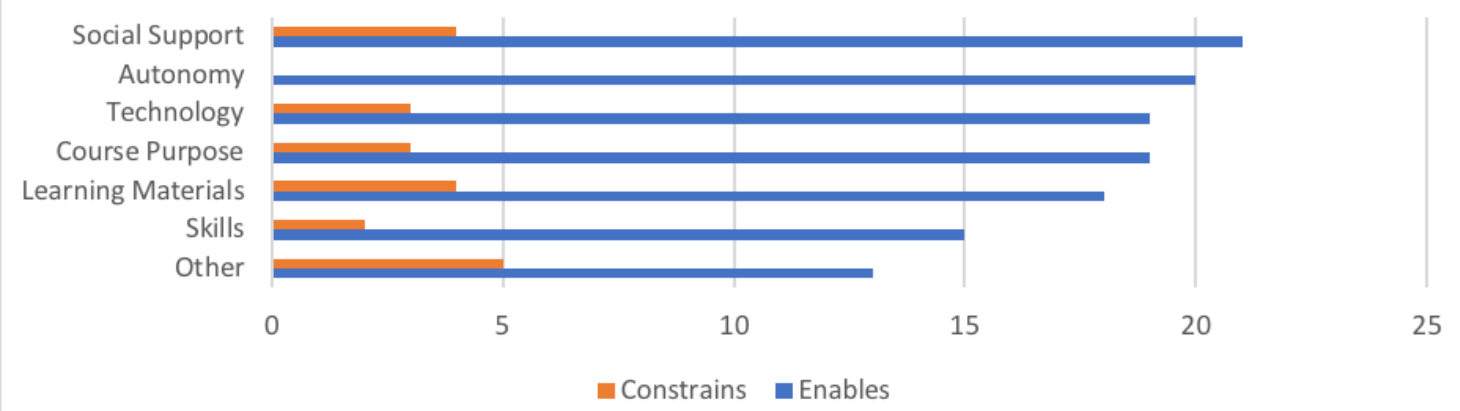

Figure 3. Frequency that the critical dimensions were noted to either enable or constrain learning in the more successful programs $(N=12)$ in the study (on a scale of $0-24$ )

In the less successful programs, social support and autonomy were noted to constrain almost as much as they were noted to enable. For example, less successful programs tended to enable learning by choosing a foundation-level topic and purpose and providing learning materials via a suitable technology. In the more successful programs, however, social support and autonomy features were strong enablers. These findings suggest a revision to the first logic proposition of the model that, while each dimension is present, their importance is not equal. Social support and autonomy seem to be particularly important to the development of equitable online programs and need to be considered explicitly in the design process.

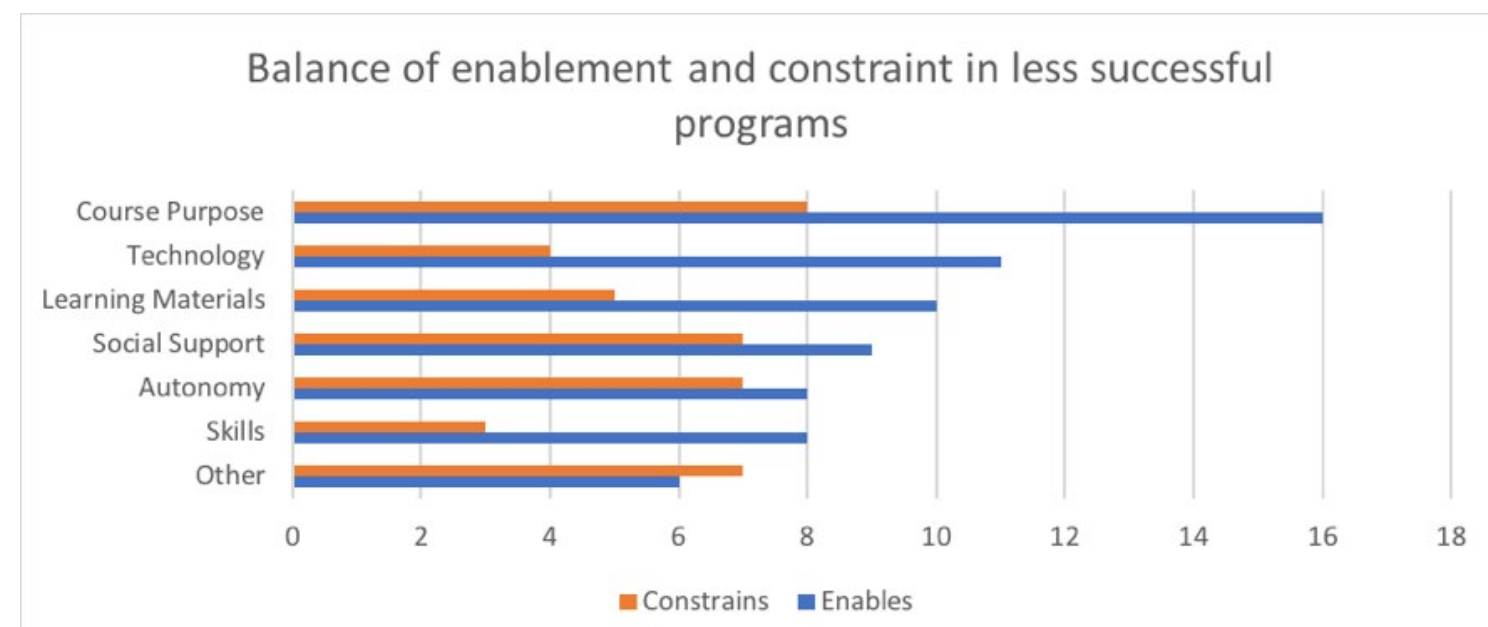

Figure 4. Frequency that the critical dimensions were noted to either enable or constrain learning in the less successful programs $(N=10)$ in the study (on a scale of $0-20$ )

In terms of P3 (impact of learner agency), there was less evidence of agency in the synthesis of the case studies' aims and findings than the level of evidence for the six critical dimensions. This is likely to be related to the fact that the studies did not have an interest in learner agency and were focused on other areas. However, where problems occurred in any of the critical dimensions, learner agency could be seen to help solve the issues in ways that aligned with learners' priorities and values. Examples were provided in the studies for particular instances of learner workarounds for unplanned situations or design features that created unintended consequences for some learners. Therefore, the data tentatively confirmed the approach of valuing learner agency in course designs identified in the literature review and influencing the definitions 
of the conceptual model. Learner agency is recommended as the focus for future research to complement understandings of success factors focused on teaching and institutional provision.

The next section addresses the range or variations within each dimension as a basis for revising the model, including verifying how the dimensions work together to enable or constrain learning.

\section{Results: clarifying the specifics of the dimensions in context}

This section revises the definitions of each dimension in light of a qualitative synthesis that identified important enablers within and across each dimension.

There were some unexpected and specific findings that helped clarify the definitions of all six dimensions. In addition, the data also suggested dimension amplifications, that is, one dimension amplifying the effect of another dimension, as a new proposition of how the dimensions work together in the conceptual model. The following section outlines the findings and is followed by a summary in Table 3.

The notion of course purpose seems a broad notion, that is, to learn topic X; however, the study found more specific types of purposes contributed to the access, progress and success of disadvantaged learners: to learn a particular foundational topic online $(N=14)$ and to enable a group of learners to learn together $(N$ $=8)$.

Although the number is smaller, programs that aimed to enable a group of learners tended to perform better. They included five of the seven studies with excellent learner outcomes - those rated as exceeding their self-reported aims. By designing courses catering to the need for a defined community group of learners to learn together, for example, an existing network of bilingual schoolteachers, it seems easier to pitch the right type of course and to provide an in-built peer support network. The programs with a purpose of enabling a group of learners also tended to feature foundation-level topics, often of pre-existing importance to learners. Examples of pre-existing groups who learnt together included families with special needs children (McDougall et al., 2016); three studies on three continents of regional teachers in low-resource contexts upskilling in ICT and English (Charbonneau-Gowdy et al., 2015; Colas et al., 2016; Wolfenden et al., 2017); and first-year maths students using a MOOC as a free supplementary resource in a study group context (N. Li et al., 2015).

The data broadly supported the definition of learning materials, particularly regarding the use of a range of media and provision for multilingual resources and facilitation to encompass learner cultural-linguistic diversity. However, coherent learning sequences, the provision of choice and feedback, authentic experts and/or compelling stories of first-hand experience were some other more specific enabling aspects of learning materials.

In addition, the analysis found that some studies actively sought to empower those diverse learners by reducing the power and status gaps between teachers and learners and between levels of learners. Examples included student-sourced learning materials (S. W. Li \& Mitros, 2015); allocation of learners as project leaders (Celina et al., 2016); learners with disabilities exploring then teaching parents and family members how to use apps on mobile devices (McDougall et al., 2016); and the validation of learners' strengths and lived experiences as a form of expertise (King et al., 2014; Watson et al., 2016).

Beyond the simple definition of autonomy as freedom to learn at no cost, and at the time and place of the learners' choosing, two specific additional forms of empowerment were also found within the autonomy dimension: choice and control over learning tasks and application to personal context and concerns.

In this study, the definition of the social support dimension was found to require changing to cover technical, motivational, emotional and academic support for both learning to learn and knowledge and skills for a specific domain or task. Social support was not limited to peers, as teachers and facilitators of the online programs tended to contribute across the whole spectrum of support, with relationships being built up during the length of the course.

The studies often noted how crucial study companions were to learners' outcomes, in both fully distance and online modes as well as in blended modes where local study groups helped orient new learners to online 
platforms, and these were often organised around weekly tasks and online content. As a result of these findings, which indicate the breadth of learner support goes beyond social elements, I have renamed the social support dimension learner support in the final, modified conceptual model.

In addition, there was sometimes a tension or balance to be achieved between the social support and autonomy dimensions. Making one dimension compulsory tended to come at the expense of the other. The implications are that designers might need to consider striking a balance between both dimensions and how they work together in the design process.

\section{Dimension amplifications: new logic of the model}

The analysis of the data for the technology dimension revealed unexpected results. Free technology was not found to directly enable learning in most cases. While free access to online courses was an essential starting point, the technology was found to have no power to retain learners or produce outcomes or change on the basis of its features or affordances. Provision of free handheld devices for learning where the participants did not have alternatives was critical but was noted by authors as important in only two studies. This element may be important in future research with a higher proportion of very low resource contexts. However, technology was found to regularly amplify and enhance the other dimensions, most notably social support, learning materials and autonomy. The technology amplification occurred by providing particular features to enhance the accessibility of the materials, reduce the confusability or complexity of the materials or enhance the communications and teamwork between learners. These are important issues which argue for keeping technology as a legitimate dimension of digital equity models, rather than positioning the technology in the background as neutral enablers of pedagogy, as in online learning models such as CoI and TD. I would argue that, in terms of digital inequality, we are naïve to think of technology as a neutral or benevolent enabler of learners, particularly in light of data privacy, artificial intelligence and ethics. Therefore, it might be better to keep technology in the model with a definition to guide design decisions that promote ethical and equitable use.

Some studies identified the online forums as providing for a diversity of views and experiences, where study companions as dual practitioner and learners became powerful enablers for shifting views and attitudes. This positively impacted both emotions and knowledge. In this way, the views of study companions (part of learner support) became a new and alternative form of learning materials that embraces broader views of knowledge and expertise than traditional academic-as-expert video lectures. This was also the case for programs where lurkers benefitted from others' postings.

Table 3 summarises the findings and also lists how each dimension enabled and constrained.

Table 3

Summary of course dimension themes as enablers and constraints

\begin{tabular}{|c|c|c|}
\hline $\begin{array}{l}\text { Critical } \\
\text { dimension }\end{array}$ & Enabled & Constrained \\
\hline Technology & $\begin{array}{l}\text { Enabled by amplifying other dimensions. } \\
\text { Two cases enabled by providing free } \\
\text { handheld devices and language resources for } \\
\text { which learners had no alternatives. }\end{array}$ & $\begin{array}{l}\text { In the Global South, a lack of } \\
\text { laptops, power or Internet; in the } \\
\text { Global North, unwanted platform or } \\
\text { tool features, complexity, confusion } \\
\text { or overwhelm; lock-step } \\
\text { progression or forcing of } \\
\text { behaviours (constrains autonomy). }\end{array}$ \\
\hline Course purpose & $\begin{array}{l}\text { Enabled groups of learners to learn together; } \\
\text { and learning a foundational topic online; } \\
\text { consulting with a community of potential } \\
\text { users in the development phase to avoid } \\
\text { mismatching the course purpose with learner } \\
\text { concerns. }\end{array}$ & $\begin{array}{l}\text { Use of a school location for adult } \\
\text { learning (negative prior experiences } \\
\text { and feelings about schooling); } \\
\text { negative remedial approaches; } \\
\text { MOOC was not embedded in a } \\
\text { compulsory remedial program; } \\
\text { biased program assessment } \\
\text { experienced by some as forcing } \\
\text { attitudinal change; an overly long } \\
\text { ( } 36 \text { week) uncertified program. }\end{array}$ \\
\hline
\end{tabular}




\section{Learning} materials

Learner
support (ex.
Social support)

Autonomy
Learner skills
(In the original
model - Skills)
Proposed logic
of the
conceptual
model

New logic of the conceptual model: one dimension can amplify another
Multilingual; range of media; coherent sequences; choice and feedback; showcasing authentic expertise; and empowering diversity including validating learners' life experiences as expertise, beginner learners teaching peers/family members, and studentsourced or -created learning materials

Multidimensional academic, technical and motivational support

Note: One study identified 25 students as the critical mass for online forum activity (Colas et al., 2016).

Freedom to learn at no cost, and at the time and place of the learners' choosing; option to tailor assessment tasks to learners' own interests; ability to apply learning to one's own life concerns.

Scaffolded technical, online learning and study skills including teamwork.

Three draft proposals detailing the logic behind how the dimensions combine to explain why program enablements and constraints were confirmed, with autonomy and learner support found to be particularly important.

Technology mostly amplified other dimensions, particularly social support, learning materials and autonomy. Study companions (subset of learner support) can amplify diversity of learning materials.
Enforced minimum assignment word limits (quantity rather than quality); lack of well curated and sequenced resources; or materials pitched to a higher level without options for more foundational learning support; dense textbook not in their first language.

Heated online forum discussions needing additional facilitation to balance strongly differing views; lack of facilitator input to clarify group-think confusion; limited forum use, i.e., lacking critical mass of regular posters; face-to-face support used over online support leading to limited online take-up, i.e., problem for students who cannot attend face-to-face sessions Inadequate learner interaction with peers or teachers can lead to isolation, i.e., imbalance between autonomy and social support

Lack of sense-making and wayfinding skills in cMOOCs; insufficient English or timemanagement skills. $\mathrm{n} / \mathrm{a}$

\section{Summary: revised definitions for the model}

Based on the previous sections, the proposed six critical dimensions for widening online participation model has been revised with modified definitions for the dimensions. The dimension previously called social support was renamed learner support in acknowledgement of the breadth of supports offered by both teachers and learning companions. The term social support could still be used to refer to the motivational and emotional elements of learner support. Peer support may still be used to identify conversations and actions of peers, to the exclusion of teachers. Skills in the original model are renamed learner skills for the education-specific context.

Because the empirical data reported more enablements than constraints, the updated definitions for the six critical dimensions have been framed positively. The revised dimensions therefore describe how this study found they could best widen online participation:

(1) Technology: accessible, ethical and easy-to-use online platforms with good mobile and Wi-Fifriendly options; amplifies other design dimensions; provides free laptops or hand-held devices in the absence of any other options 
(2) Course purpose: foundation topics of pre-existing interest including those designed for preexisting groups; aims to improve socio-economic opportunities for learners with limited prior education; widening participation rather than reinforcing existing inequalities

(3) Learning materials: inclusive of learner sociocultural and linguistic diversity; range of media open to language translation; coherent sequences; choice and feedback; showcasing authentic and diverse expertise; and empowering diversity of views, backgrounds and experience

(4) Learner support: multidimensional academic, technical and motivational support from teachers, mentors, peers and social networks that learners already know

(5) Learner skills: scaffolding to incrementally develop technical and study skills so that the inequalities of previous educational opportunities and skills are overcome

(6) Autonomy: learning at any time with control over where, when and how learners study; ability to contribute without gendered or social pressure; task choice and application to one's own life and goals.

To summarise, the findings support the three research propositions and additionally propose a fourth way of understanding the interrelationships between the dimensions:

(1) Each of the six critical dimensions will be present in the design or experience of the course to some degree and each will influence the outcomes; however, autonomy and learner support have more influence on learner outcomes; therefore, they need particular attention.

(2) Each of the six critical dimensions can either enable or constrain learners and more successful courses enable more than they constrain.

(3) Learner agency (goals, motivations, acting to overcome constraints within each dimension) influences course outcomes in addition to the six dimensions.

(4) Some dimensions (particularly the technology dimension) can amplify others.

Figure 5 shows a visualisation of the model including the full names and definitions of all the dimensions as well as the interrelationships and amplifications.

\section{CRITICAL DIMENSIONS}

for widening online participation

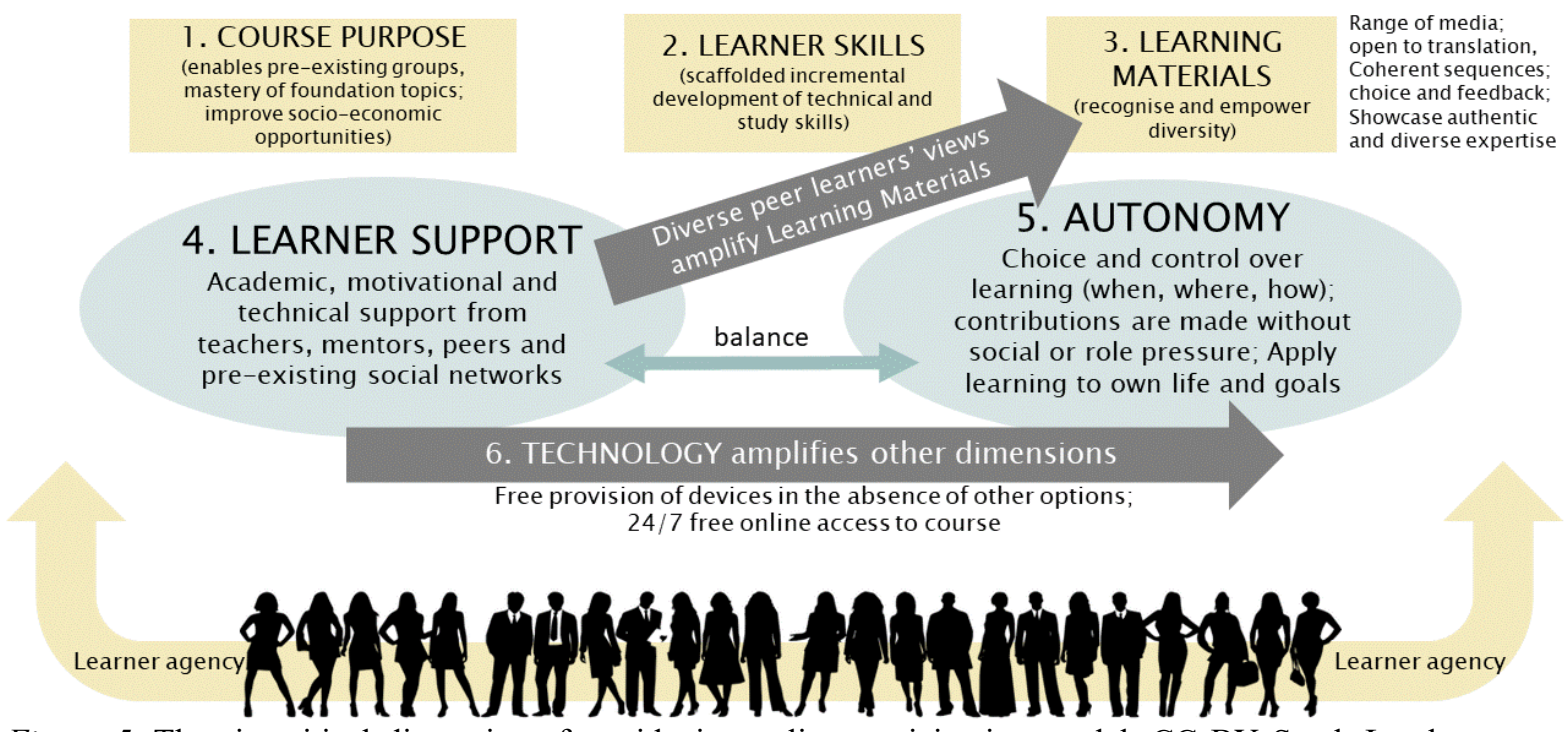

Figure 5. The six critical dimensions for widening online participation model, CC BY Sarah Lambert (2020) 


\section{Discussion}

This study adds to the body of literature that promotes the role of the learner, their communities and sociocultural contexts as important to learner outcomes, and therefore as important dimensions of conceptual models. The study also supports research which cautions against overemphasising either the influence of the technology or of a learner's agency and social settings, and calls for a balance between the two (Oliver, 2011; Selwyn, 2013). Instead, the results of this study suggest that when technology provides a suite of tools that support both the social context of learning and the need for learners' autonomy and choice about what, when and how they learn, it becomes a more powerful enabler for learning.

When combined with a learners' strengths and agency, the empowering features of the course purpose, learning materials and autonomy dimensions provide multiple opportunities to redress power imbalances and unequal outcomes between more- and less-privileged learners.

The findings about empowerment as an important enabling component of both learning materials and autonomy are reminiscent of similar work on learner empowerment and democratic design epistemologies within open education, teacher training and learning design (Czerniewicz \& Walji, 2017; Whitchurch, 2008; Zeichner, Payne, \& Brayko, 2015). If they are designed with the idea of reducing power and status gaps, it seems that open online courses can deliver a kind of levelling experience and become a third space or context in which "some individuals surrender outward status and come together to engage more as equals" (Zeichner et al., 2015, p. 3). Therefore, the notion of online classes as third spaces for learner empowerment, as well as places for democratic design collaborations, seems congruent with widening participation agendas and a fruitful area for future research.

The study also adds insight into the debate about whether blended learning and maintaining some face-toface contact is necessary to support non-privileged learners. This study suggests that foundational and nonprivileged learners can succeed in a wide range of face-to-face and online contexts. Similar to the finding in a recent large-scale study of American community college learners (Shea \& Bidjerano, 2018), the optimum blend of online learning depended less on the learner and more on the provider's experience with designing for quality-supported online learning.

However, the finding that programs delivered at a distance tended to have more mixed outcomes than those with some face-to-face delivery argues for caution in making the decision about online and/or face-to-face support. It may be that particular learning objectives require blended support, such as the three studies where scaffolded skills development was the whole purpose of the program (Charbonneau-Gowdy et al., 2015; Chen \& Chen, 2015; McDougall et al., 2016).

This article offers a new model which takes advantage of MOOC experience in provision to globally diverse learners at scale (Kent \& Bennett, 2017). MOOCs have provided massive amounts of data and new opportunities for research into online design and provision (Breslow et al., 2013), including how we can develop online learning in ways that do not further perpetuate digital inequality and digital divides (Lambert, 2020). In terms of the final definitions of the model, course purpose is the only dimension to noticeably reflect community-based MOOCs and free programs while the other dimensions seem generalisable to inclusive fee-paying online and blended programs, and this is also a suggested area for additional research. It seems likely that with additional testing for different online contexts, the course purpose definition - and perhaps other definitions - can be revised to be useful for specific variations of online and distance learning.

To summarise, while this study has used instances of free online programs as examples to develop a new conceptual model, it also seems very likely to hold value for mainstream (for-fee) online provision, which increasingly needs to widen participation to engage new markets and remain financially viable. As mainstream higher education seeks to widen participation, it also promotes bursaries, grants, loans and scholarships to remove, reduce or delay payment for study so that costs are less of a barrier. Perhaps the difference between what is needed to enable non-privileged learners to succeed in for-fee online courses is not so different to what is needed in free online programs. In an era of widening participation for both free and for-fee online courses, implementing the six critical dimensions could be a useful form of inclusive design for all learners, from both privileged and non-privileged backgrounds. This would be an 
improvement to the current situation for MOOCs in particular, which have espoused "education for all" but as noted in the literature review, have a habit of reaching and enabling the privileged and already educated.

\section{Limitations of the data and areas for future research}

The sample of 22 studies is considered reasonable for qualitative synthesis, and a diverse range of topics, approaches, numerous global contexts and both distance and blended approaches to free online programs were covered. In addition, the very large number of students surveyed in the primary studies, that is, over 32,000 , suggests the synthesis is based on comprehensive data. However, it is possible further research with different study samples and applications could find that different dimensions are more evident, prominent or important to outcomes. This is particularly the case with the learner skills and autonomy dimensions, which were reported on in detail in under half the sample cases.

The matters that some studies were largely silent on - in other words, the unreported features - are also a limitation. It is quite likely that any future studies which explicitly set out to design for and then investigate all six dimensions would collect better data on the relative importance of the dimensions and the interactions and amplifications between them. Future research that explicitly investigates constraints would be important, as these were generally underreported, in line with current understanding on reporting bias in educational studies (Dawson \& Dawson, 2018).

Imperfect measures of disadvantage are also a problem, and there was sometimes a lack of clarity about learner demographics within the studies. Some studies within the systematic review tested their programs on university students, while many were regional and likely to have a higher proportion of lower socioeconomic learners than elite institutions. It would be better if studies reported more consistently on the socio-economic, regional or gender disadvantage of their learner cohorts in their particular global context.

It would be useful for future research to expand the number of studies and types of online courses investigated, which might provide variations to the definitions and kinds of amplifications at play in particular online and distance learning contexts. The impact of learner agency in the light of constraining features is also an area for additional future research. Future research could also assess the extent to which such a model is useful as the basis for design guidance in the development of new programs.

\section{Conclusion}

This article contributes a new conceptual model that explains why some online educational programs engage and enable disadvantaged learners and others do not. It is hoped that the model might be useful as a design guide for staff in the development of more inclusive and effective online programs. such as those with a widening participation objective. The model includes dimensions focused on what institutions can offer as well as dimensions focused on the strengths and motivations that diverse learners bring to their learning. The final revised model provides concrete definitions of the six critical dimensions and details how the dimensions work together.

The model has been shown to be useful for explaining the enablement of socioculturally and linguistically diverse learners in open online programs including those blended with face-to-face support such as study groups. The model should facilitate online course and program designs that take into account the particular local, sociocultural contexts of learners, their motivations, agency, autonomy and the social resources they bring to the learning environment. It therefore makes a contribution to updating the conceptual and evidence base of research into digital equity.

Therefore, it is hoped that this study will add to the growing body of literature on widening participation and online education which considers learners' sociocultural diversity as an asset to both educational institutions and the process of teaching and learning.

\section{Acknowledgements}

The data collection and analysis phases of this study were supported by a $\mathrm{PhD}$ scholarship from Deakin University. I would like to thank my supervisors Professor David Boud, Associate Professor Phillip 
Dawson, Dr Joanna Tai and Dr Nadine Zacharias, who are currently or were previously with the Centre for Research in Assessment and Digital Learning at Deakin University for their guidance and support.

\section{References}

Anderson, T., \& Dron, J. (2011). Three generations of distance education pedagogy. The International Review of Research in Open and Distributed Learning, 12(3), 80-97. https://doi.org/10.19173/IRRODL.V12I3.890

Archer, M. S. (2003). Structure, agency and the internal conversation. Cambridge, United Kingdom: Cambridge University Press.

Barak, M., Watted, A., \& Haick, H. (2016). Motivation to learn in massive open online courses: Examining aspects of language and social engagement. Computers \& Education, 94, 49-60. https://doi.org/10.1016/j.compedu.2015.11.010

Bates, T. (2012, August 5). What's right and what's wrong about Coursera-style MOOCs [Blog post]. Online Learning and Distance Education Resources. Retrieved from https://www.tonybates.ca/2012/08/05/whats-right-and-whats-wrong-about-coursera-style-moocs/

Bearman, M., \& Dawson, P. (2013). Qualitative synthesis and systematic review in health professions education. Medical Education, 47(3), 252-260. https://doi.org/10.1111/medu.12092

Beaven, T., Hauck, M., Comas-Quinn, A., Lewis, T., \& de los Arcos, B. (2014). MOOCs: Striking the right balance between facilitation and self-determination. MERLOT Journal of Online Learning and Teaching, 10(1), 31-43. Retrieved from http://jolt.merlot.org/vol10no1/beaven 0314.pdf

Bennett, A., Southgate, E., \& Shah, M. (2016). Global perspectives on widening participation: Approaches and concepts. In M. Shah, A. Bennett, \& E. Southgate (Eds.), Widening higher education participation: A global perspective (p. 241-253). Waltham, MA: Chandos. https://doi.org/10.1016/B978-0-08-100213-1.00015-9

Biesta, G., Allan, J., \& Edwards, R. (2011). The theory question in research capacity building in education: Towards an agenda for research and practice. British Journal of Educational Studies, 59(3), 225-239. https://doi.org/10.1080/00071005.2011.599793

Bonk, C. J., Zhu, M., Kim, M., Xu, S., Sabir, N., \& Sari, A. R. (2018). Pushing toward a more personalized MOOC: Exploring instructor selected activities, resources, and technologies for MOOC design and implementation. International Review of Research in Open and Distance Learning, 19(4), 92-115. https://doi.org/10.19173/irrodl.v19i4.3439

Bozkurt, A., Akgün-Özbek, E., \& Zawacki-Richter, O. (2017). Trends and patterns in massive open online courses: Review and content analysis of research on MOOCs (2008-2015). The International Review of Research in Open and Distributed Learning, 18(5). https://doi.org/10.19173/irrodl.v18i5.3080

Bozkurt, A., Kilgore, W., \& Crosslin, M. (2017). Bot-teachers in hybrid massive open online courses (MOOCs): A post-humanist experience. Australasian Journal of Educational Technology, 34(3). https://doi.org/10.14742/ajet.3273

Breslow, L., Pritchard, D. E., DeBoer, J., Stump, G. S., Ho, A. D., \& Seaton, D. T. (2013). Studying learning in the worldwide classroom: Research into edX's first MOOC. Research \& Practice in Assessment, 8, 13-25. Retrieved from http://www.rpajournal.com/dev/wpcontent/uploads/2013/05/SF2.pdf

Brown, R. H., Barram, D. J., \& Irving, L. (1995). Falling through the Net: A survey of the "have nots" in rural and urban America. Washington, DC: United States Department of Commerce. Retrieved from https://www.ntia.doc.gov/ntiahome/fallingthru.html

Butcher, N. (2015). A basic guide to open educational resources (OER). Paris, France: UNESCO \& Commonwealth of Learning. Retrieved from http://oasis.col.org/handle/11599/36

Case, J. M. (2013). Researching student learning in higher education: A social realist approach. London, United Kingdom: Routledge \& the Society for Research into Higher Education. https://doi.org/https://doi.org/10.4324/9780203797402

Celina, H., Kharrufa, A., Preston, A., Comber, R., \& Olivier, P. (2016). SOLE meets MOOC: Designing infrastructure for online self-organised learning with a social mission. In Proceedings of the 2016 ACM Conference on Designing Interactive Systems (pp. 484-496). New York, NY: ACM. https://doi.org/10.1145/2901790.2901848

Charbonneau-Gowdy, P., Capredoni, R., Gonzalez, S., Jayo, M. J., \& Raby, P. (2015). Working the three T's: Teacher education, technology and teacher identities. In A. Jefferies \& M. Cubric (Eds.), ECEL 2015: Proceedings of the 14th European Conference on e-Learning (pp. 138-146). Sonning 
Common, United Kingdom: Academic Conferences Limited.

Chen, Y.-H., \& Chen, P.-J. (2015). MOOC study group: Facilitation strategies, influential factors, and student perceived gains. Computers \& Education, 86, 55-70. https://doi.org/10.1016/j.compedu.2015.03.008

Colas, J.-F., Sloep, P. B., \& Garreta-Domingo, M. (2016). The effect of multilingual facilitation on active participation in MOOCs. The International Review of Research in Open and Distributed Learning, 17(4), 280-314. https://doi.org/10.19173/irrodl.v17i4.2470

Colvard, N. B., Watson, C. E., \& Park, H. (2018). The impact of open educational resources on various student success metrics. International Journal of Teaching and Learning in Higher Education, 30(2), 262-276. Retrieved from http://www.isetl.org/ijtlhe/pdf/IJTLHE3386.pdf

Conole, G. (2013, January 11). Current thinking on the 7Cs of learning design [Blog post]. e4innovation.com. Retrieved from $\mathrm{http} / / / \mathrm{e} 4$ innovation.com/? $\mathrm{p}=628$

Czerniewicz, L., \& Walji, S. (2017). MOOCs, community orientation and reclaiming the social justice agenda. Retrieved from https://youtu.be/3frjnQqhQSs

Daniel, J. (2012). Making Sense of MOOCs: musings in a maze of myth, paradox and possibility. Journal of Interactive Media in Education, 3. https://doi.org/10.5334/2012-18

Davis, D., Chen, G., Zee, T. Van Der, Hauff, C., Houben, G., van der Zee, T., ... Houben, G. (2016). Retrieval practice and study planning in MOOCs: Exploring classroom-based self-regulated learning strategies at scale. In K. Verbert, M. Sharples, \& T. Klobučar (Eds.), EC-TEL 2016: Proceedings of the 11th European Conference on Technology Enhanced Learning (pp. 57-71). Cham, Switzerland: Springer. https://doi.org/10.1007/978-3-319-45153-4_5

Dawson, P., \& Dawson, S. L. (2018). Sharing successes and hiding failures: "Reporting bias" in learning and teaching research. Studies in Higher Education, 43(8), 1405-1416. https://doi.org/10.1080/03075079.2016.1258052

Devlin, M. (2012). Effective teaching and support of students from low socioeconomic status backgrounds: Practical advice for teaching staff. Retrieved from http://www.lowses.edu.au/

Devlin, M. (2018). Teaching inclusively online in a massified university system. Widening Participation and Lifelong Learning, 20(1), 146-166. https://doi.org/10.5456/WPLL.20.1.146

DiMaggio, P., \& Hargittai, E. (2001). From the 'digital divide'to 'digital inequality': Studying Internet use as penetration increases (Working Paper Series, 15). Princeton, NJ: Princeton University. Retrieved from https://culturalpolicy.princeton.edu/sites/culturalpolicy/files/wp15 dimaggio hargittai.pdf

Emanuel, E. J. (2013). Online education: MOOCs taken by educated few. Nature, 503(7476), 342-342. https://doi.org/10.1038/503342a

Engstrom, C., \& Tinto, V. (2008). Access without support is not opportunity. Change, 40(1), 46-51. https://doi.org/10.3200/CHNG.40.1.46-50

Finfgeld, D. L. (2003). Metasynthesis: The state of the art - So far. Qualitative Health Research, 13(7), 893-904. https://doi.org/10.1177/1049732303253462

Finfgeld-Connett, D. (2014). Use of content analysis to conduct knowledge-building and theorygenerating qualitative systematic reviews. Qualitative Research, 14(3), 341-352. https://doi.org/10.1177/1468794113481790

Florian, L., \& Black-Hawkins, K. (2011). Exploring inclusive pedagogy. British Educational Research Journal, 37(5), 813-828. https://doi.org/10.1080/01411926.2010.501096

Funes, M., \& Mackness, J. (2018). When inclusion excludes: a counter narrative of open online education. Learning, Media and Technology, 43(2), 119-138. https://doi.org/10.1080/17439884.2018.1444638

Garrison, D. R. (2000). Theoretical challenges for distance education in the 21 st century: A shift from structural to transactional issues. The International Review of Research in Open and Distributed Learning, 1(1). https://doi.org/10.19173/irrodl.v1i1.2

Garrison, D. R., Anderson, T., \& Archer, W. (2010). The first decade of the community of inquiry framework: A retrospective. Internet and Higher Education, 13(1-2), 5-9. https://doi.org/10.1016/j.iheduc.2009.10.003

Goldberg, L. R., Bell, E., King, C., O’Mara, C., McInerney, F., Robinson, A., \& Vickers, J. (2015). Relationship between participants' level of education and engagement in their completion of the Understanding Dementia Massive Open Online Course. BMC Medical Education, 15(1). https://doi.org/10.1186/s12909-015-0344-z

Gorski, P. C. (2003). Digital quity. In G. L. Anderson \& K. Herr (Eds.), Encyclopedia of activism and social justice (pp. 458-461). Thousand Oaks, CA: Sage. 
Gorski, P. C. (2009). Insisting on digital equity: Reframing the dominant discourse on multicultural education and technology. Urban Education, 44(3), 348-364. https://doi.org/10.1177/0042085908318712

Howard, S., \& Maton, K. (2011). Theorising knowledge practices: A missing piece of the educational technology puzzle. ALT-J: Research in Learning Technology, 19(3), 191-206. https://doi.org/10.1080/21567069.2011.624170

Hyman, P. (2013, October 23). MOOCs evolve; version 2.0 aims to retain more students [Blog post]. Communications of the ACM. Retrieved from https://cacm.acm.org/news/168966-moocs-evolveversion-2-0-aims-to-retain-more-students/fulltext

Kang, H., \& Gyorke, A. S. (2008). Rethinking distance learning activities: A comparison of transactional distance theory and activity theory. Open Learning, 23(3), 203-214. https://doi.org/10.1080/02680510802420050

Kent, M., \& Bennett, R. (2017). What was all that about? Peak MOOC hype and post-MOOC legacies. In R. Bennett \& M. Kent (Eds.), Massive open online courses and higher education: what went right, what went wrong and where to next? (pp. 1-191). London, United Kingdom: Routledge.

King, C., Doherty, K., Kelder, J. A., McInerney, F., Walls, J., Robinson, A., \& Vickers, J. (2014). 'Fit for purpose': A cohort-centric approach to MOOC design. International Journal of Educational Technology in Higher Education, 11(3), 108-121. https://doi.org/10.7238/rusc.v11i3.2090

Kozan, K., \& Caskurlu, S. (2018). On the Nth presence for the Community of Inquiry framework. Computers and Education, 122, 104-118. https://doi.org/10.1016/j.compedu.2018.03.010

Lambert, S. R. (2020). Do MOOCs contribute to student equity and social inclusion? A systematic review 2014-18. Computers \& Education, 145. https://doi.org/10.1016/j.compedu.2019.103693

Laurillard, D., \& Kennedy, E. (2017). The potential of MOOCs for learning at scale in the Global South (Working paper no. 31). London, United Kingdom: Center for Global Higher Education. Retrieved from http://www.researchcghe.org/perch/resources/publications/wp31.pdf

Law, P. (2015). Digital badging at The Open University: Recognition for informal learning. Open Learning: The Journal of Open, Distance and E-Learning, 30(3), 1-14. https://doi.org/10.1080/02680513.2015.1104500

Li, N., Kidziński, Ł., \& Dillenbourg, P. (2015). Augmenting collaborative MOOC video viewing with synchronized textbook. In J. Abascal, S. Barbosa, M. Fetter, T. Gross, P. Palanque, \& M. Winkler (Eds.), INTERACT 2015: Proceedings of the IFIP Conference on Human-Computer Interaction (pp. 81-88). Cham, Switzerland: Springer. https://doi.org/10.1007/978-3-319-22668-2 7

Li, S., Tang, Q., \& Zhang, Y. (2016). A case study on learning difficulties and corresponding supports for learning in cMOOCs. Canadian Journal of Learning and Technology, 42(2), 1-26. https://doi.org/10.21432/t2gs4s

Li, S. W. D., \& Mitros, P. (2015). Learnersourced recommendations for remediation. In Proceedings of the 15th International Conference on Advanced Learning Technologies (pp. 411-412). Piscatawy, NJ: IEEE. https://doi.org/10.1109/ICALT.2015.72

Liff, S., Shepherd, A., Wajcman, J., Rice, R., \& Hargittai, E. (2004). An evolving gender digital divide?. OII Internet Issue Brief, 2. https://doi.org/10.2139/ssrn.1308492

MacKinnon, L., \& Bacon, L. (2016). How to develop a GROOC: Establishing group dynamics in MOOCs. In There and Back: Charting Flexible Pathways in Open, Mobile and Distance Education: Proceedings of the DEANZ Biennial Conference. Retrieved from http://gala.gre.ac.uk/17250/2/17250\%20MACKINNON_How to Develop a GROOC 2016.pdf

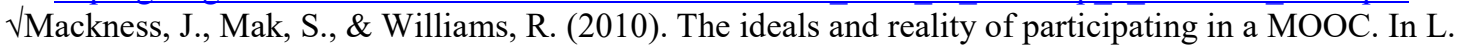
Dirckinck-Holmfeld, V. Hodgson, C. Jones, M. de Laat, D. McConnell, \& T. Ryberg (Eds.), Proceedings of the 7th International Conference on Networked Learning (pp. 266-275). Lancaster, United Kingdom: University of Lancaster. Retrieved from https://www.lancaster.ac.uk/fss/organisations/netlc/past/nlc2010/abstracts/PDFs/Mackness.pdf

$\sqrt{ }$ Mackness, J., \& Pauschenwein, J. (2016). Visualising structure and agency in a MOOC using the Footprints of Emergence framework. In S. J. Crammer, N. Bonderup-Dohn, M. De Laat, T. Ryberg, \& J.-A. Syme (Eds.), Proceedings of the 10th International Conference on Networked Learning 2016 (pp. 278-286). Lancaster, United Kingdom: Lancaster University. Retrieved from http://www.research.lancs.ac.uk/portal/en/publications/proceedings-of-the-tenth-internationalconference-on-networked-learning-2016(1c761e42-974b-4b1b-b775-4dd9564da58f)/export.html

MacLeod, K. R., Swart, W. W., \& Paul, R. C. (2019). Continual improvement of online and blended teaching using relative proximity theory. Decision Sciences Journal of Innovative Education, 17(1), 53-75. https://doi.org/10.1111/dsji.12169 
McDougall, J., Readman, M., \& Wilkinson, P. (2016). From digital literacy to capability: Project report and impact evaluation. Bournemouth, United Kingdom: Bournemouth University. Retrieved from http://eprints.bournemouth.ac.uk/23531/

Milligan, C., \& Littlejohn, A. (2016). How health professionals regulate their learning in massive open online courses. The Internet and Higher Education, 31, 113-121. https://doi.org/10.1016/j.iheduc.2016.07.005

Moore, M. G. (1993). Theory of transactional distance. In D. Keegan (Ed.), Theoretical principles of distance education (pp. 22-38). New York, NY: Routledge

Moore, M. G., Resta, P., Rumble, G., Tait, A., \& Zaparovanny, Y. (2002). Open and distance learning: Trends, policy and strategy considerations. Paris, France: UNESCO.

Mountford-Zimdars, A., Sabri, D., Moore, J., Sanders, J., Jones, S., \& Higham, L. (2015). Causes of differences in student outcomes. Bristol, United Kingdom: Higher Education Funding Council for England. Retrieved from https://dera.ioe.ac.uk/23653/1/HEFCE2015_diffout.pdf

Murugesan, R., Nobes, A., \& Wild, J. (2017). A MOOC approach for training researchers in developing countries. Open Praxis, 9(1), 45-57. https://doi.org/10.5944/openpraxis.9.1.476

Negroponte, N., Bender, W., Battro, A., \& Cavallo, D. (2006, February). One laptop per child. Keynote address at the National Educational Computing Conference in San Diego, CA. Retrieved from http://www.olpcnews.com/presentations/olpc-nov-2006t.pdf

Oliver, M. (2011). Technological determinism in educational technology research: Some alternative ways of thinking about the relationship between learning and technology. Journal of Computer Assisted Learning, 27(5), 373-384. https://doi.org/10.1111/j.1365-2729.2011.00406.x

Paul, R. C., Swart, W., Zhang, A. M., \& MacLeod, K. R. (2015). Revisiting Zhang's scale of transactional distance: refinement and validation using structural equation modeling. Distance Education, 36(3), 364-382. https://doi.org/10.1080/01587919.2015.1081741

Pawson, R., Greenhalgh, T., Harvey, G., \& Walshe, K. (2005). Realist review: A new method of systematic review designed for complex policy interventions. Journal of Health Services Research \& Policy, 10(suppl 1), 21-34. https://doi.org/10.1258/1355819054308530

Pérez-Sanagustín, M., Hernández-Correa, J., Gelmi, C., Hilliger, I., \& Rodriguez, M. F. (2016,). Does taking a MOOC as a complement for remedial courses have an effect on my learning outcomes? A pilot study on calculus. In K. Verbert, M. Sharples, \& T. Klobucar (Eds.), Proceedings of the European Conference on Technology Enhanced Learning (pp. 221-233). Cham, Switzerland: Springer. Retrieved from https://link.springer.com/book/10.1007\%2F978-3-319-45153-4?externallink-new-window

Rohs, M., \& Ganz, M. (2015). MOOCs and the claim of education for all: A disillusion by empirical data. The International Review of Research in Open and Distributed Learning, 16(6). https://doi.org/10.19173/irrodl.v16i6.2033

Sandelowski, M., Voils, C. I., Leeman, J., \& Crandell, J. L. (2012). Mapping the mixed methods-mixed research synthesis terrain. Journal of Mixed Methods Research, 6(4), 317-331. https://doi.org/10.1177/1558689811427913

Selwyn, N. (2013). distrusting educational technology critical questions for changing times. London, United Kingdom: Taylor \& Francis.

Shea, P., \& Bidjerano, T. (2018). Online course enrollment in community college and degree completion: The tipping point. The International Review of Research in Open and Distributed Learning, 19(2). https://doi.org/10.19173/irrodl.v19i2.3460

Simpson, O. (2008). Motivating learners in open and distance learning: Do we need a new theory of learner support? Open Learning: The Journal of Open and Distance Learning, 23(3), 159-170. https://doi.org/10.1080/02680510802419979

Stenbom, S. (2018). A systematic review of the Community of Inquiry survey. The Internet and Higher Education, 39, 22-32. https://doi.org/10.1016/j.iheduc.2018.06.001

Stich, A. E., \& Reeves, T. D. (2017). Massive open online courses and underserved students in the United States. Internet and Higher Education, 32, 58-71. https://doi.org/10.1016/j.iheduc.2016.09.001

Stone, C. (2017). Opportunity through online learning. Retrieved from https://www.ncsehe.edu.au/wpcontent/uploads/2017/03/CathyStone EQUITY-FELLOWSHIP-FINAL-REPORT-1.pdf

Tait, A. (2015). Student success in open, distance, and e-learning (The ICDE report series). Oslo, Norway: The International Council for Open and Distance Education. Retrieved from https://static1.squarespace.com/static/5b99664675f9eea7a3ecee82/t/5bb8ec2aa4222f8e88078db2/153 8845743577/studentsuccessreport.pdf

Tekin, C., Braun, J., \& van der Schaar, M. (2015, April). etutor: Online learning for personalized 
education. In V. Clarkson \& J. Manton (Eds.), Proceedings of the 2015 IEEE International Conference on Acoustics, Speech and Signal Processing (ICASSP) (pp. 5545-5549). Piscataway, NJ:

IEEE. Retrieved from https://ieeexplore.ieee.org/xpl/conhome/7158221/proceeding

Thomas, J., Barraket, J., Ewing, S., MacDonald, T., Mundell, M., \& Tucker, J. (2016). Measuring Australia's digital divide: The Australian digital inclusion index 2016. Melbourne, Australia: Swinburne University of Technology \& Telstra. Retrieved from http://digitalinclusionindex.org.au/theindex-report/report/

Traver, A. E., Volchok, E., Bidjerano, T., \& Shea, P. (2014). Correlating community college students ' perceptions of community of inquiry presences with their completion of blended courses. The Internet and Higher Education, 20, 1-9. https://doi.org/10.1016/j.iheduc.2013.09.001

Trow, M. (2007). Reflections on the transition from elite to mass to universal access: Forms and phases of higher education in modern societies since WWII. In J. J. F. Forest \& P. G. Altbach (Eds.), International handbook of higher education (pp. 243-280). Dordrecht, The Netherlands: Springer. https://doi.org/10.1007/978-1-4020-4012-2_13

Warschauer, M. (2003). Technology and social inclusion: Rethinking the digital divide. Cambridge, MA: MIT Press.

Watson, S. L., Loizzo, J., Watson, W. R., Mueller, C., Lim, J., \& Ertmer, P. A. (2016). Instructional design, facilitation, and perceived learning outcomes: an exploratory case study of a human trafficking MOOC for attitudinal change. Educational Technology Research and Development, 64(6), 12731300. https://doi.org/10.1007/s11423-016-9457-2

Wen, M., Yang, D., \& Rosé, C. P. (2015). Virtual teams in massive open online courses. In C. Conati, N. Heffernan, A. Mitrovic, \& M. Felisa Verdejo (Eds.), Proceedings of the International Conference on Artificial Intelligence in Education (pp. 820-824). Cham, Switzerland: Springer. https://doi.org/10.1007/978-3-319-19773-9

Whitchurch, C. (2008). Shifting identities and blurring boundaries: The emergence of third space professionals in UK higher education. Higher Education Quarterly, 62(4), 377-396. https://doi.org/10.1111/j.1468-2273.2008.00387.x

Whitmer, J., Schiorring, E., James, P., \& Miley, S. (2015). How students engage with a remedial English writing MOOC: A case study in learning analytics with big data. Louisville, CO: EDUCAUSE. Retrieved from https://library.educause.edu/ /media/files/library/2015/3/elib1502-pdf.pdf

Wolfenden, F., Cross, S., \& Henry, F. (2017). MOOC adaptation and translation to improve equity in participation. Journal of Learning for Development - JL4D, 4(2). Retrieved from http://j14d.org/index.php/ej14d/article/view/209/243

Wood, D., Scutter, S., \& Viljoen, R. (2016). Evidenced-based approach to the design and redevelopment of inclusive technology enhanced learning environments (Final Report). Canberra, Australia: Australian Government Department of Education and Training. Retrieved from https://nla.gov.au/nla.obj-555469989/view

Yosso, T. J. (2005). Whose culture has capital? A critical race theory discussion of community cultural wealth. Race Ethnicity and Education, 8(1), 69-91. https://doi.org/10.1080/1361332052000341006

Zeichner, K., Payne, K. A., \& Brayko, K. (2015). Democratizing teacher education. Journal of Teacher Education, 66(2), 122-135. https://doi.org/10.1177/0022487114560908

Corresponding author: Sarah Lambert, sarah.lambert@deakin.edu.au

Copyright: Articles published in the Australasian Journal of Educational Technology (AJET) are available under Creative Commons Attribution Non-Commercial No Derivatives Licence (CC BY-NC-ND 4.0). Authors retain copyright in their work and grant AJET right of first publication under CC BY-NC-ND 4.0.

Please cite as: Lambert, S. R. (2019). Six critical dimensions: A model for widening participation in open, online and blended programs. Australasian Journal of Educational Technology, 35(6), 161-182. https://doi.org/10.14742/ajet.5683 